\title{
OS ESTUDOS SOBRE DEFICIÊNCIA NA EDUCAÇÃO'
}

\author{
Adriano Henrique Nuernberg**
}

$\mathrm{O}$

O livro Ressignificando a deficiência: da abordagem social às práticas inclusivas na escola ${ }^{1}$ de autoria de Jan W. Valle (The City College/NY) e David J. Connor (Hunter College/NY), representa um marco para os estudos sobre deficiência no país. Seus autores são experientes pesquisadores oriundos da área de Educação Especial nos Estados Unidos, onde publicaram diversos artigos e livros, além de terem sido premiados por seus trabalhos acadêmicos sobre deficiência e inclusão.

Esse é o primeiro livro de caráter internacional, publicado no Brasil, que apresenta o campo acadêmico conhecido como Disability Studies in Education (Estudos sobre Deficiência na Educação), derivado dos Disability Studies (DINIZ, 2007; BARNES, OLIVER; BARTON, 2008) e que traz uma abordagem crítica para o fenômeno da deficiência no contexto educacional. Surgido nos Estados Unidos no final da década de 1990, esse campo nasce da crítica à corrente biomédica da Educação Especial e busca ampliar as perspectivas sobre a natureza da deficiência.

Os autores desse livro partem do modelo social da deficiência para avaliar o impacto ético, social e pedagógico da perspectiva biomédica da deficiência. Comprometidos com os princípios de justiça social e a Educação Inclusiva, seus argumentos vão na direçáo da necessidade de transformaçáo do ambiente pedagógico para que todos possam aprender. Reconhecendo a deficiência como um marcador de identidades, assim como as categorias de gênero, geração, raça e orientação sexual, os Estudos sobre Deficiência na Educaçâo (ESDE) focam prioritariamente as relaçóes e os lugares sociais da deficiência no contexto da variação corporal humana. (BAGLIERI, 2011)

O livro está dividido em três partes que buscam articular o conhecimento e a prática da educação inclusiva.

\footnotetext{
* Resenha do livro Ressignificando a deficiência: da abordagem social às práticas inclusivas na escola, da autoria de Jan W. Valle e David J. Connor, publicado pela McGraw-Hill Editora, em 2014, com 240p. ISBN 9788580553420.

** Universidade Federal de Santa Catarina, Departamento de Psicologia, Florianópolis, SC., Brasil. E-mail de contato: adriano.nuernberg@ufsc.br.
} 
A primeira parte é composta por quatro capítulos e se intitula "Como o conhecimento orienta a prática”. Seu objetivo principal é analisar criticamente as crenças hegemônicas sobre deficiência e Educação Especial, situando marcos da legislação americana, revisando a história da educação de crianças com deficiência e avaliando o impacto da Educação Inclusiva nesse contexto. Sua maior contribuição, contudo, é a análise da relação das concepçóes de deficiência com as práticas escolares, onde o modelo médico é duramente criticado em seu compromisso com a segregação. É no terceiro capítulo que essa crítica ganha mais espaço, onde os autores problematizam a noção de normalidade e seus efeitos no circuito técnico, administrativo e pedagógico percorrido pela criança diagnosticada com alguma deficiência até a chegada na escola comum. Já no quarto capítulo os autores analisam a inclusão como uma questão de justiça social e exploram situações concretas extraídas do contexto escolar, levantando aspectos éticos e sociais que emergem na prática da Educação Inclusiva. Aliás, a leitura dessa primeira parte do livro torna-se interessante pela opção dos autores por uma narrativa pessoal que ilustra determinados momentos da história da escolarização pública e também pelo teor crítico que imprimem à análise da relação entre a Educação e o contexto macroeconômico.

A segunda parte do livro, também composta por quatro capítulos, intitula-se "Como a prática aprofunda o conhecimento" e objetiva identificar subsídios à prática da Educação Inclusiva. Trata-se de apresentar encaminhamentos compromissados com a educação de todos os alunos e que consideram a diversidade tanto como condição inerente às turmas, quanto como pressuposto fundamental do planejamento pedagógico. Dentre os subsídios apresentados, destacam-se o princípio do desenho universal, o foco nos estilos singulares de aprendizagem, a teoria das inteligências múltiplas e a taxonomia de Bloom, que consiste numa estratégia de ensino por meio de perguntas organizadas em diferentes níveis de conhecimento e com atividades versáteis de sala de aula. Além desses conceitos e práticas de ensino, os autores também atentam para a importância da avaliação, que deve ser consistente, diversificada e flexível para que todos os alunos possam demonstrar seus conhecimentos e habilidades. (MORTON, 2012) Isso tudo é abordado entre os capítulos 5 e 7, cabendo ao capítulo 8 a discussão sobre a necessidade de estabelecer uma relação integrada e colaborativa do professor de educação geral com o professor de educação especial.

A última parte do livro abrange os capítulos "Desafiando ativamente a normalidade" (capítulo 9) e "Promovendo crenças e práticas inclusivas" (capítulo 10). Como os títulos sugerem, os autores buscam, na parte final, desafiar o leitor a rever estereótipos sobre a deficiência para pavimentar o caminho da mudança de atitude pedagógica necessária à Educação Inclusiva. Para tanto, enfrentam a questão histórica do silêncio e da invisibilidade da deficiência produzida pelo desconforto que se assenta no mito da homogeneidade do alunado. Em contrapar- 
tida, propóem a celebração das diferenças como um princípio basilar da vida em comunidade e a concepção de deficiência como uma variação humana legítima, digna e natural. Tais ideias constituem a base dos Estudos sobre Deficiência na Educação, cujo potencial, como visto acima, é extremamente fecundo ao debate sobre a Educação Inclusiva.

A despeito do livro ser uma tradução do original em inglês publicado, de 2011, em Nova Iorque e inserir-se na história e realidade da política de Educação Inclusiva estadunidense, suas contribuições para o contexto brasileiro são altamente relevantes. Além dos problemas conceituais, políticos e pedagógicos serem semelhantes aos da nossa realidade educacional, o livro articula o debate teórico com a sugestão de princípios educacionais e encaminhamentos práticos que subsidiam a intervenção pedagógica e a construção da Educação Inclusiva.

Como se evidencia na estrutura do livro, a relaçáo do conhecimento com a prática é o fio condutor dos argumentos na perspectiva dos Estudos sobre Deficiência na Educação. Com isso, os autores convidam os educadores a reverem a produção científica em torno da Educação Especial, fazendo-os pensar sobre pressupostos naturalizados em relação à pessoa com deficiência nesse contexto.

No Brasil não é novo o debate crítico sobre a Educação Especial, tendo em vista a larga produção de autores preocupados em rever seus fundamentos e as diretrizes das políticas públicas. Autores como Sadao Omote (Unesp), Júlio Romero Ferreira (Unimep) Rosana Glat (Uerj), Rosângela Prieto (USP), José Geraldo Bueno (PUC-SP), além de vários pesquisadores e pesquisadoras ligados à Associação Nacional de Pós-Graduação e Pesquisa em Educação (Anped) e à Associação Brasileira de Pesquisadores em Educação Especial (Abpee), vêm fazendo a crítica à política de Educação Especial e às concepções que a fundamentam no país. Contudo, a contribuição dos Estudos sobre Deficiência na Educação para esse debate consiste exatamente no enfoque oriundo dos Disability Studies (DINIZ, 2007), que concebe a deficiência como inerente à condição humana e como expressão de sua variação corporal. Isso nos compromete a repensar o caminho das adaptaçóes e encaminhamentos que submetem o estudante com deficiência aos parâmetros da normalidade a partir de um modelo que enfatiza o déficit. Assim, esse livro contribui para superar a concepção normativa de aluno e os desdobramentos desta nos princípios basilares da Educação em termos das barreiras atitudinais, instrumentais, pedagógicas e programáticas que impedem a participação plena dos estudantes com deficiência.

Enfim, trata-se de um excelente livro a ser citado e utilizado em programas de formação de professores que enfrentam o desafio da inclusão escolar de crianças, jovens e adultos com deficiência e referenciado por aqueles que buscam subsídios à crítica da perspectiva biomédica, que historicamente constituiu a Educação Especial. 
Os estudos sobre deficiência na educação

\section{Notas}

1. VALLE, J. W.; CONNOR, D. J. Rethinking Disability: A Disability Studies Approach to Inclusive Practices. 1st ed. New York: The McGraw-Hill, 2011. ISBN 978-0073526041.

\section{Referências}

BAGLIERI, S. et al. Disability Studies in Education: The Need for a Plurality of Perspectives on Disability. Remedial and Special Education, v. 32, n. 4, p. 267-278, 2011.

BARNES, C.; OLIVER, M.; BARTON, L. Disability Studies Today. Cambridge/UR UK: Polity Press, 2008.

DINIZ, D. O que é deficiência? São Paulo: Brasiliense, 2007.

MORTON, M. Using DSE to Notice, Recognize and Respond' to Tools of Exclusion and Opportunities for Inclusion in New Zealand. Review of Disability Studies: An International Journal, v. 8, n. 3, p. 25-34, 2012.

Recebido em 25 de abril de 2014.

Aprovado em 29 de junho de 2015.

DOI: http://dx.doi.org/10.1590/ES0101-73302015134028 